\title{
Correlation of Radiation Pneumonitis History Before Nivolumab with Onset of Interstitial Lung Disease and Progression-free Survival of Patients with Pre-treated Advanced Non-small Cell Lung Cancer
}

\author{
AKIHIRO TAMIYA ${ }^{1}$, MOTOHIRO TAMIYA ${ }^{2}$, KENJI NAKAHAMA ${ }^{1}$, YOSHIHIKO TANIGUCHI ${ }^{1}$, \\ TAKAYUKI SHIROYAMA ${ }^{3}$, SHUN-ICHI ISA ${ }^{4}$, TAKAKO INOUE ${ }^{2}$, KYOICHI OKISHIO $^{4}$, KAZUMI NISHINO $^{2}$, \\ TORU KUMAGAI ${ }^{2}$, HIDEKAZU SUZUKI ${ }^{3}$, TOMONORI HIRASHIMA ${ }^{3}$, FUMIO IMAMURA ${ }^{2}$ and SHINJI ATAGI ${ }^{4}$ \\ ${ }^{1}$ Department of Internal Medicine, National Hospital Organization Kinki-chuo Chest Medical Center, Osaka, Japan; \\ ${ }^{2}$ Department of Thoracic Oncology, Osaka International Cancer Institute, Osaka, Japan; \\ ${ }^{3}$ Department of Thoracic Malignancy, Osaka Habikino Medical Center, Osaka, Japan; \\ ${ }^{4}$ Department of Clinical Research Center, \\ National Hospital Organization Kinki-chuo Chest Medical Center, Osaka, Japan
}

\begin{abstract}
Background/Aim: Nivolumab has a promising efficacy for patients with non-small-cell lung cancer (NSCLC) as second-line or later treatment, and after radiotherapy as abscopal effect. However, the effects of radiation pneumonitis history before nivolumab have not been clarified. Therefore, we retrospectively analyzed the correlation of a history of radiation pneumonitis before nivolumab with onset of interstitial lung disease (ILD) and progression-free survival (PFS) after nivolumab treatment in patients with previously treated NSCLC. Patients and Methods: A total of 201 patients treated with nivolumab were retrospectively reviewed. We collected clinical data of patients at the time of starting nivolumab and we evaluated ILD incidence and PFS in relation to patient characteristics, including radiation pneumonitis history. Results: The median age was 68 years; 135 patients were men, 157 had a smoking history, and 153 had performance status of 0 or 1. Thirty-four patients experienced radiation pneumonitis before nivolumab, and 50 patients received radiotherapy to the chest (31 patients received curative radiotherapy). The overall median PFS was 2.8 months and the overall ILD rate
\end{abstract}

Correspondence to: Akihiro Tamiya, MD, Department of Internal Medicine, National Hospital Organization Kinki-chuo Chest Medical Center, 1180 Nagasonecho, Kita-ku, Sakai, Osaka 5918555, Japan. Tel: +81 722523021, Fax: +81 722523041, e-mail: atamiya@kch.hosp.go.jp

Key Words: Nivolumab, progression-free survival, radiation pneumonitis, interstitial lung disease. was $12.4 \%$. Higher ILD incidence was observed in the group with a history of radiation pneumonitis (26.5\%) compared to the group without radiation pneumonitis (9.6\%). The median PFS was 3.6 and 2.3 months, respectively. On multivariate analysis, a history of radiation pneumonitis was also significantly correlated with good PFS ( $p=0.023)$. Conclusion: Although increasing the risk of ILD, a history of radiation pneumonitis before nivolumab also contributes to the prolongation of PFS after nivolumab.

The immune checkpoint inhibitors nivolumab and pembrolizumab are antibodies to programmed death-1 (PD1) that were recently approved by the US Food and Drug Administration and the Japanese Pharmaceuticals and Medical Devices Agency (PMDA) for patients with previously treated advanced non-small-cell lung cancer (NSCLC). Specifically, nivolumab is a fully humanized immunoglobulin G4 antibody that binds to PD-1 receptor on activated immune cells to disrupt its interaction with PD-L1 and PD-L2 ligands. Nivolumab was approved for both squamous and non-squamous NSCLC based on two phase III randomized controlled trials demonstrating increased overall survival (OS) compared to standard second-line therapy using docetaxel $(1,2)$. Pembrolizumab was approved after a phase III study ultimately confirmed a survival advantage after pembrolizumab administration as a second-line therapy over docetaxel in PD-L1-positive patients (3). As marked and durable responses have been reported in a number of patients with NSCLC treated with nivolumab and pembrolizumab, many studies have focused on identifying predictors of benefit for such patients. 
PD-L1 is the most-studied and well-known biomarker. The trial of pembrolizumab demonstrated a correlation between increased PD-L1 expression (tumor proportion score $\geq 1 \%$, as required by the PMDA) and improved outcomes (3). However, the role of PD-L1 as a biomarker for nivolumab therapy is less well-defined. Although PD-L1 expression in tumor cells was associated with improved survival after nivolumab treatment compared to docetaxel in patients with non-squamous histology (2), no association between PD-L1 expression and outcomes was observed in a trial that enrolled patients with squamous-cell histology (1). Furthermore, even in non-squamous cases, responses to nivolumab were observed in patients without PD-L1 expression. Since PDL1 is not a biomarker predictive of nivolumab efficacy, novel predictive markers of efficacy are required to define the patient population that derives a permanent benefit from nivolumab therapy.

It is also noteworthy that immune checkpoint inhibitors are associated with immune-related adverse events, including interstitial lung disease (4). Previous reports showed that the incidence of nivolumab-related death due to ILD was higher in patients with NSCLC compared with those with other cancer types, such as melanoma $(5,6)$. However, the ILD risk in patients with NSCLC undergoing nivolumab treatment is unclear.

A radiation-induced regression in tumor lesions distant from the targeted site has been known for six decades as a rare unexplained phenomenon in patients receiving local radiotherapy (7), and this phenomenon was called abscopal phenomenon. Recently, some reports suggested that this abscopal effect may result from an immunogenic type of cancer cell death $(8,9)$. In support of this phenomenon, radiation pneumonitis was observed in patients treated with ipilimumab and fractionated radiotherapy (RT) (10). However, the relationship between RT to the chest as local RT and nivolumab treatment effects, including ILD, remains unclear. Therefore, we retrospectively analyzed the correlation of a history radiation pneumonitis before nivolumab treatment with risk of onset of ILD, and progression-free survival (PFS) after nivolumab treatment in patients with NSCLC.

\section{Patients and Methods}

Patients and study design. We conducted a retrospective multicenter study of patients treated with nivolumab $(3 \mathrm{mg} / \mathrm{kg}$ intravenously every 2 weeks) and who had previously been treated for advanced NSCLC at the National Hospital Organization Kinki-chuo Chest Medical Center, Osaka International Cancer Institute, and Osaka Habikino Medical Center between December 17, 2015, the date that nivolumab was approved in Japan, and July 31, 2016. Patients were excluded from our analysis if they received nivolumab as part of a clinical trial, or if any additional anti-neoplastic therapies were administered concurrently. A total of 201 patients were identified under these criteria. All participants provided written informed
Table I. Patient characteristics.

\begin{tabular}{lc}
\hline Characteristic & $\mathrm{N}=201$ \\
\hline $\begin{array}{l}\text { Median age (range), years } \\
\quad \text { Median (range) }\end{array}$ & $68(27-87)$ \\
Gender, $\mathrm{n}$ & \\
$\quad$ Male/female & $135 / 66$ \\
PS, $\mathrm{n}$ & \\
$\quad$ O/1/2/3/4 & $32 / 121 / 33 / 12 / 3$ \\
Histology, $\mathrm{n}$ & \\
$\quad$ SQ/Ad/other & $42 / 142 / 17$ \\
Smoking status & \\
$\quad$ Yes/no & $157 / 44$ \\
EGFR mutation, $\mathrm{n}$ & \\
$\quad$ Positive/negative/unknown & $36 / 128 / 37$ \\
History of RT to chest, $\mathrm{n}$ & \\
$\quad$ Yes/no & $50 / 151$ \\
History of radiation pneumonitis, $\mathrm{n}$ & \\
$\quad$ Yes/no & $34 / 167$ \\
\hline
\end{tabular}

Ad: Adenocarcinoma; EGFR: epidermal growth factor receptor; PS: performance status; RT: radiotherapy; SQ: squamous carcinoma.

consent to participation in this study. The study protocol was approved by the Institutional Review Board of the three institutions. This study was registered at UMIN; UMIN-ID: UMIN000025908.

Data collection and evaluation. We collected the electronic medical records and pharmacy databases, including age and Eastern Cooperative Oncology Group performance status (ECOG PS) at the time of initiating nivolumab, gender, smoking history, histology, treatments before nivolumab and response to them, history of radiation pneumonitis and thoracic RT (palliative or curative), and baseline complete blood count defined as that within 2 weeks prior to nivolumab administration. Epidermal growth factor receptor $(E G F R)$ and ALK receptor tyrosine kinase $(A L K)$ mutation status was also reported; importantly, these data were available if such profiling was performed as part of routine clinical care. We also retrospectively evaluated the response to nivolumab, using the Response Evaluation Criteria in Solid Tumors (RECIST) version 1.1 criteria (11). Furthermore, we collected data on the incidence of nivolumab-related ILD.

The primary outcome was PFS, defined as the number of days between the first administration of nivolumab and death, or disease progression, or the last patient contact. Secondary outcomes were the overall response rate (ORR) and the incidence of nivolumabrelated ILD. ORR was calculated as the percentage of complete and partial responses among all treated patients. Nivolumab-related ILD was defined as worsened pneumonitis during treatment with nivolumab, while cases with confirmed malignant lung infiltration or infection were excluded. Patients were followed-up for disease status until November 30, 2016. All data were examined by outsourcing (EP-SOGO Co., Ltd,).

Statistical analyses. Statistical analyses were conducted using JMP statistical software program, version 11 (SAS Institute Inc., Cary, $\mathrm{NC}$, USA) to compare clinical outcomes according to history of radiation pneumonitis and thoracic RT. Survival curves were 

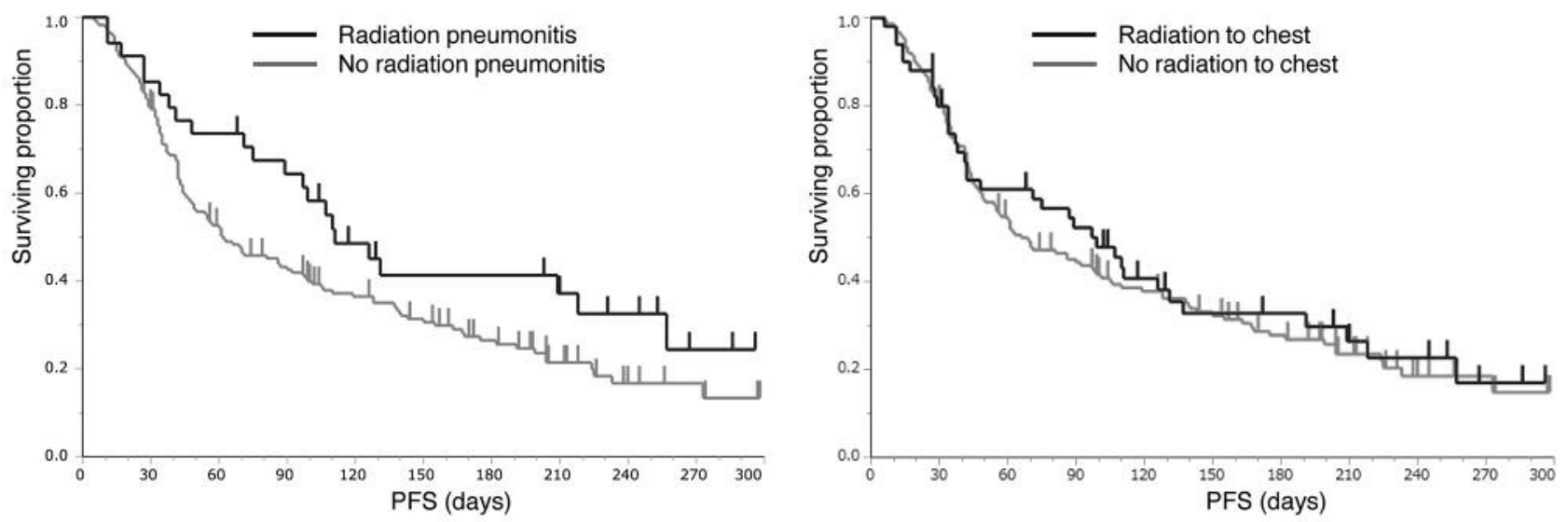

Figure 1. Kaplan-Meier curves of progression-free survival (PFS) according to history of radiation pneumonitis (a) and of radiation to the chest (b).

estimated using the Kaplan-Meier method and the differences between groups were compared by a log-rank test. Univariate and multivariate analyses were performed using the Cox proportional hazards models. Fisher's exact tests were used to compare the nonparametric variables, such as response, as well as to identify the risk factors for ILD associated with nivolumab treatment according to potential predictors, and to calculate relative risk ratio (RR) and its $95 \%$ confidence interval. $p$-Values of less than 0.05 were considered statistically significant.

\section{Results}

Patient characteristics. Between December 17, 2015 and July 31, 2016, 201 patients with pre-treated advanced NSCLC were treated with nivolumab. The characteristics of these patients nivolumab are shown in Table I. The median age was 68 years, and most of the patients were men (135 patients), had a smoking history (157 patients), and had an ECOG PS score of 0 or 1 (153 patients). Moreover, 34 patients experienced radiation pneumonitis before nivolumab therapy and 50 patients received RT to the chest; specifically, 31 patients received curative RT.

PFS after nivolumab and its correlation with history of radiation pneumonitis. For the whole cohort, the median PFS was 2.8 months. The median PFS in the group with and that without a history of radiation pneumonitis history was 3.6 and 2.3 months, respectively (Figure 1a). The median PFS in the group that had and that which had not received RT to the chest was 3.3 months and 2.2 months, respectively (Figure 1b). Regarding other factors, the median PFS was as follows: male vs. female, 3.3 vs. 1.9 months; smoking history $v s$. non-smoking history, 3.1 vs. 1.8 months; squamous $v s$. non-squamous carcinoma, $1.8 v s .3 .2$ months; and PS 0-1 vs. PS 2-4, 3.2 vs. 1.5 months.
In the univariate analysis (Table II), poor PS was significantly correlated with reduced PFS $(p=0.0023)$, while a trend for such association was observed for male gender $(p=0.169)$, smoking history $(p=0.152)$, and squamous histology $(p=0.252)$; there was also a trend for improved PFS with a history of radiation pneumonitis $(p=0.237)$. However, RT to the chest did not significantly correlate with PFS $(p=0.635)$. Furthermore, in the multivariate analysis, a history of radiation pneumonitis was observed to be a statistically significant factor in PFS ( $p=0.023)$ (Table II).

Response to nivolumab and its correlation with history of radiation pneumonitis. We summerized the response of nivolumab in Table III. In the whole patient group, the complete overall response rate (ORR), which comprises all cases with complete response (CR) plus those with partial response (PR), was $15.4 \%$, and the progressive disease (PD) rate was $44.8 \%$. Comparing the nivolumab efficacy between the radiation pneumonitis history and non-radiation pneumonitis history groups, the ORR was $8.8 \%$ and $17.4 \%(p=0.30)$, and the PD rate was $29.4 \%$ and $47.9 \%$ ( $p=0.059)$, respectively. Moreover, comparing the efficacy between the RT to the chest and no RT to the chest groups, the ORR was $10.0 \%$ and $17.9 \%$, and the PD rate was $38.0 \%$ and $47.0 \%$, respectively (Table III).

Incidence of ILD associated with nivolumab. Twenty-four out of 201 patients developed nivolumab-related ILD, with an overall ILD incidence of $12.4 \%$ during nivolumab therapy. Specifically, the incidence of ILD was significantly Iower in the group without a history of radiation pneumonitis than in that with such history ( $9.6 \%$ vs. $26.5 \%$, respectively), and in that without RT to the chest compared to that with $(9.3 \%$ vs. $22.0 \%$, respectively). On the other hand, there was no difference in the ILD incidence according to PS, gender or smoking history (Table IV). 
Table II. Univariate and multivariate Cox proportional hazards model analysis of factors associated with progression-free survival (PFS) of patients treated with nivolumab.

\begin{tabular}{|c|c|c|c|c|c|c|}
\hline \multirow[t]{2}{*}{ Factor } & \multirow[t]{2}{*}{$\mathrm{N}$} & \multirow{2}{*}{$\begin{array}{c}\text { Median PFS } \\
\text { (months) }\end{array}$} & \multicolumn{2}{|c|}{ Univariate analysis } & \multicolumn{2}{|c|}{ Multivariate analysis } \\
\hline & & & HR $(95 \% \mathrm{CI})$ & $p$-Value & $\mathrm{HR}(95 \% \mathrm{CI})$ & $p$-Value \\
\hline All patients & & 201 & 2.8 & - & & - \\
\hline \multicolumn{7}{|l|}{ Gender } \\
\hline Male & 135 & 3.3 & & & & \\
\hline Female & 66 & 1.9 & $1.27(0.90-1.78)$ & 0.169 & $1.24(0.77-1.93)$ & 0.362 \\
\hline \multicolumn{7}{|l|}{ PS } \\
\hline $0-1$ & 153 & 3.2 & & & & \\
\hline $2-4$ & 48 & 1.5 & $1.82(1.25-2.61)$ & 0.0023 & $1.96(1.33-2.82)$ & 0.0008 \\
\hline \multicolumn{7}{|c|}{ Smoking history } \\
\hline Yes & 157 & 3.1 & & & & \\
\hline No & 44 & 1.8 & $1.33(0.90-1.92)$ & 0.152 & $1.32(0.79-2.20)$ & 0.287 \\
\hline \multicolumn{7}{|l|}{ Histology } \\
\hline SQ & 42 & 1.8 & & & & \\
\hline Non-SQ & 159 & 3.2 & $0.67(0.30-1.31)$ & 0.252 & $0.59(0.38-0.93)$ & 0.023 \\
\hline \multicolumn{7}{|c|}{ History of RT to chest field } \\
\hline No & 151 & 2.2 & & & & \\
\hline Yes & 50 & 3.3 & $0.86(0.43-1.60)$ & 0.635 & - & \\
\hline \multicolumn{7}{|c|}{ History of radiation pneumonitis } \\
\hline No & 167 & 2.3 & & & & \\
\hline Yes & 34 & 3.6 & $0.67(0.31-1.28)$ & 0.237 & $0.59(0.35-0.93)$ & 0.023 \\
\hline
\end{tabular}

CI: Confidence interval; HR: hazard ratio; PS: performance status; RT: radiotherapy; SQ: squamous carcinoma.

\section{Discussion}

In the present study of 201 patients with NSCLC who received nivolumab as second-line or later treatment, history of radiation pneumonitis was not only a risk factor for developing ILD with a mean incidence of $26.5 \%$ (relative risk ratio: $2.76,95 \% \mathrm{CI}: 1.33-5.73$ ), but was also significantly predictive of better PFS, with a median PFS of 3.6 months ( $p=0.023$, in the multivariate analysis). This PFS prolongation of nivolumab was consistent with the lower PD rate $(29.4 \%)$ observed for the group with a history of radiation pneumonitis compared to that $(47.9 \%)$ observed for the group without such history. To the best of our knowledge, this study is the first analysis of the relationship between the efficacy of nivolumab and the risk for nivolumab-related ILD in a large population of patients with NSCLC, and radiation pneumonitis history before the administration of anti-PD-1 therapy in routine practice.

Data from many laboratories have indicated that local radiation produces systemic, immune-mediated, antitumor, and potentially, anti-metastatic effects (12-14). Additionally, the combination of local RT and immunomodulation not only can augment local tumor control, but can also cause distant antitumor effects (abscopal effects) through increased release of tumor antigen and antigen-presenting cell crosspresentation, improved dendritic-cell function, and enhancing $\mathrm{T}$ cell priming (15-17). Thus, radiation induces the release of chemokines that subsequently enrich the $\mathrm{T}$ cell infiltrate, and enhances priming of pre-existing or newly infiltrating T-cells, which provides a positive immunological outcome (18). In fact, the presence of tumor-infiltrating lymphocytes, especially effector T-cells, before therapy is correlated with better survival in patients with cancer (19). Furthermore, in preclinical models, inhibition of the PD 1PD L1 checkpoint combined with RT liberates T-cells from immunosuppression $(15,20)$. Therefore, history of thoracic RT and nivolumab administration have a potential synergistic effect, which prolongs PFS and reduces the PD rate. Although RT to the chest did not reflect this hypothesis of synergy effect in the present study, this may be because such immunomodulation does not occur with all types of RT. On the other hand, a history of radiation pneumonitis was associated with an improved PFS and lower PD rate. This indicates that radiation pneumonitis may reflect $\mathrm{T}$-cell infiltration in response to chemokine release after thoracic RT, and patients who were treated with nivolumab and had had previous radiation pneumonitis may have developed synergistic effects, including abscopal effects.

Nivolumab was associated with an ILD rate of 4.6-6.2\% and $7.2 \%$ in previous phase III trials $(1,2)$ and a previous Japanese clinical trial (21), respectively, which is lower than the rate of $12.4 \%$ observed in our study. Notably, compared 
Table III. Efficacy of nivolumab by factor.

\begin{tabular}{lcccccc}
\hline Factor & $\mathrm{N}$ & $\mathrm{CR}(\%)$ & $\mathrm{PR}(\%)$ & $\mathrm{SD}(\%)$ & $\mathrm{PD}(\%)$ & $\mathrm{NE}(\%)$ \\
\hline $\begin{array}{l}\text { All patients } \\
\text { Gender }\end{array}$ & 201 & 0.5 & 15.4 & 35.8 & 44.8 & 3.5 \\
$\quad$ Male & 135 & 0.7 & 17.0 & 37.8 & 40.0 & 4.4 \\
$\quad$ Female & 66 & 0.0 & 12.1 & 31.8 & 54.6 & 1.5 \\
PS & & & & & & \\
$\quad$ 0-1 & 153 & 0.7 & 17.7 & 37.9 & 40.5 & 3.3 \\
$\quad 2-4$ & 48 & 0.0 & 8.3 & 29.2 & 58.3 & 4.2 \\
Smoking history & & & & & & \\
$\quad$ Yes & 157 & 0.6 & 15.9 & 38.2 & 40.8 & 4.5 \\
$\quad$ No & 44 & 0.0 & 13.6 & 27.3 & 59.1 & 0.0 \\
History of RT & & & & & & \\
to chest field & & & & & & \\
$\quad$ No & 151 & 0.0 & 17.9 & 31.8 & 47.0 & 3.3 \\
$\quad$ Yes & 50 & 2.0 & 8.0 & 48.0 & 38.0 & 4.0 \\
History of radiation & & & & & & \\
pneumonitis & & & & & & \\
$\quad$ No & 167 & 0.0 & 17.4 & 30.5 & 47.9 & 4.2 \\
$\quad$ Yes & 34 & 2.9 & 5.9 & 61.8 & 29.4 & 2.9 \\
\hline
\end{tabular}

PS: Performance status; RT: radiotherapy; CR: complete response; PR: partial response; SD: stable disease; PD: progression disease; NE: not evaluated.

to these trials, which led to the approval of nivolumab for NSCLC, our cohort had inferior PS and larger number of patients with a history of radiation pneumonitis. Given these key differences, it is not surprising that the incidence of nivolumab-related ILD in our cohort was higher than that in published trials.

This is the first report to demonstrate that previous radiation pneumonitis is a risk factor for nivolumab-related ILD, likely because of radiation recall pneumonitis caused by nivolumab. Radiation recall pneumonitis is a specific form of radiation pneumonitis precipitated by certain pharmacological agents. Some reports have demonstrated that radiation recall pneumonitis can be caused by cytotoxic chemotherapy or EGFR-tyrosine kinase inhibitor (22-26). It was also shown that radiation recall pneumonitis is an acute inflammatory reaction occurring in a previously irradiated area of lung tissue $(25,27)$, because radiation promotes the release of danger signals and chemokines, which recruit inflammatory cells into the tumor microenvironment, including antigen-presenting cells that activate cytotoxic $\mathrm{T}$ cell function, and, by contrast, immunosuppressive cells into the tumor microenvironment (18). On the other hand, immune-related adverse events associated with nivolumab or ipilimumab include dermatitis, endocrinopathies, colitis, hepatitis, and pneumonitis, which are all thought to arise from aberrant activation of autoreactive T-cells $(28,29)$. In addition, PD-1 can induce negative feedback to attenuate innate immune inflammatory responses and tissue damage
Table IV. Rate of interstitial lung disease (ILD) with nivolumab therapy and relative risk of ILD by factor.

\begin{tabular}{|c|c|c|c|c|}
\hline Factor & $\mathrm{N}$ & $\begin{array}{l}\text { ILD incidence } \\
(\%)\end{array}$ & $\begin{array}{l}\text { Relative risk } \\
\text { ratio }(95 \% \mathrm{CI})\end{array}$ & $p$-Value \\
\hline All patients & & 201 & 12.4 & - \\
\hline \multicolumn{5}{|l|}{ Gender } \\
\hline Male & 135 & 14.1 & & \\
\hline Female & 66 & 9.1 & $0.65(0.27-1.54)$ & 0.37 \\
\hline \multicolumn{5}{|l|}{ PS } \\
\hline $0-1$ & 153 & 13.1 & & \\
\hline $2-4$ & 48 & 10.4 & $0.80(0.32-2.01)$ & 0.80 \\
\hline \multicolumn{5}{|c|}{ Smoking history } \\
\hline Yes & 157 & 13.4 & & \\
\hline No & 44 & 9.1 & $0.68(0.25-1.88)$ & 0.61 \\
\hline \multicolumn{5}{|c|}{$\begin{array}{l}\text { History of RT } \\
\text { to chest field }\end{array}$} \\
\hline No & 151 & 9.3 & & \\
\hline Yes & 50 & 22.0 & $2.37(1.15-4.88)$ & 0.03 \\
\hline \multicolumn{5}{|c|}{$\begin{array}{l}\text { History of radiation } \\
\text { pneumonitis }\end{array}$} \\
\hline No & 167 & 9.6 & & \\
\hline Yes & 34 & 26.5 & $2.76(1.33-5.73)$ & 0.018 \\
\hline
\end{tabular}

CI: Confidence interval; PS: performance status; RT: radiotherapy.

elicited by Toll-like receptors and cytokine signaling (30). Therefore, nivolumab might cause excessive activation of immune cells by blocking the PD-1-PD-L1 pathway that negatively regulates immune response. As a result, a high incidence of nivolumab-related ILD, including radiation recall pneumonitis, might occur in response to nivolumab.

There are several limitations to the present study. Firstly, given the retrospective nature of the study, there is a potential for bias and confounding in the investigation of PFS. Therefore, we attempted to address confounding by building multivariate models to adjust for confounding factors. Secondly, very few patients underwent PD-L1 testing, and we were unable to include PD-L1 status as a potential confounding or interacting variable in our analyses. PD-L1 states is not routinely tested in patients with NSCLC outside of clinical trials in Japan, due to the availability of nivolumab in second-line or later setting without PD-L1 testing.

\section{Conclusion}

In summary, a history of radiation pneumonitis is independently associated not only with nivolumab-related risk of ILD, but also with prolonged PFS and lower PD rate in patients with advanced NSCLC treated with nivolumab. Therefore, it is important to take action for preventing ILD development when using nivolumab treatment for patients with a history of radiation pneumonitis, increasing the potential for 
better PFS. However, it is unclear whether previous radiation pneumonitis is a prognostic factor, and further studies are warranted to determine the utility of a history of radiation pneumonitis in the context of other predictive markers.

\section{Funding}

This study was supported by Ono pharmaceutical Co., Ltd and Bristol-Myers Squibb Co., Ltd.

\section{Conflicts of Interest}

Dr. Y. Taniguchi, Dr. A. Tamiya, Dr. S. Isa, Dr. K. Nakahama, Dr. T. Shiroyama, Dr. H. Suzuki, Dr. T. Inoue, Dr. M. Tamiya, Dr. T. Hirashima, Dr. F. Imamura, and Dr. S. Atagi report grants from Ono Pharmaceutical and Bristol-Myers Squibb. Dr. Y. Taniguchi, Dr. A. Tamiya, Dr. T. Shiroyama, Dr. H. Suzuki, Dr. M. Tamiya, Dr. T. Hirashima, Dr. F. Imamura, and Dr. S. Atagi report personal fees from Ono Pharmaceutical. Dr. Y. Taniguchi, Dr. A. Tamiya, Dr. M. Tamiya, Dr. T. Hirashima, Dr. F. Imamura, and Dr. S. Atagi report personal fees from Bristol-Myers Squibb during the conduct of the study. Dr. Y. Taniguchi reports personal fees from Chugai Pharmaceutical outside the submitted work. Dr. A. Tamiya reports personal fees from Chugai Pharmaceutical, AstraZeneka, Eli Lilly, and Boehringer Ingelheim outside the submitted work. Dr. K. Okishio reports personal fees from Ono Pharmaceutical outside the submitted work. Dr. T. Shiroyama reports personal fees from Taiho Pharmaceutical, Boehringer Ingelheim, and AstraZeneca outside the submitted work. Dr. H. Suzuki reports personal fees from Taiho Pharmaceutical, Boehringer Ingelheim, Pfizer, and Eli-Lilly outside the submitted work. Dr. M. Tamiya reports personal fees from Chugai Pharmaceutical, Pfizer, AstraZeneca, Taiho Pharmaceutical, Eli Lilly, Asahi Kasei Pharmaceutical, Daichi Sankyo CO. LTD. Alere Medical and Boehringer Ingelheim outside the submitted work. Dr. K. Nishino reports personal fees from Chyugai, Boehringer Ingelheim, Eli Lilly, and AstraZeneca outside the submitted work. Dr. T. Kumagai reports personal fees from Ono Pharmaceutical, Astra Zeneca, and Boehringer Ingelheim outside the submitted work. Dr. T. Hirashima reports grants and personal fees from MSD Oncology, Lilly Japan, AstraZeneca, Chugai Pharma, and Boehringer Ingelheim, grants from Eisai, Daiichi Sankyo, Merck Serono, Taiho Pharmaceutical, Kyowa Hakko Kirin, and Takeda, and personal fees from Bayer outside the submitted work. Dr. F. Imamura reports personal fees from Pfizer Inc., AstraZeneca K. K., Novartis Pharma K. K., Kyowa Hakko Kirin Co. Ltd., Boehringer Ingelheim GmbH, Taiho Pharmaceutical Co. Ltd., Eli Lilly Japan K. K., Chugai Pharmaceutical Co. Ltd. outside the submitted work. Dr. S. Atagi reports grants from Pfizer, Chugai Pharmaceutical, AstraZeneca, MSD, Taiho Pharmaceutical, Yakult Pharmaceutical Industry, Eli Lilly, and Boehringer Ingelheim, and personal fees from Taiho Pharmaceutical, Chugai Pharmaceutical, AstraZeneca, Eli Lilly, and Boehringer Ingelheim outside the submitted work.

\section{Research Involving Human Participants}

Ethical approval: The study protocol was approved by the Institutional Review Board of the three participants' institutions. This study was registered at UMIN; UMIN-ID: UMIN000025908.

\section{Informed Consent}

Informed consent was obtained from all individual participants included in the study.

\section{Acknowledgements}

The Authors wish to thank all the participating patients and to thank Ono Pharmaceutical Co., Ltd and Bristol-Myers Squibb Co., Ltd for supporting the study, and EP-SOGO Co., Ltd, for collecting the clinical data. Additionally, the Authors wish to thank Editage (www.editage.jp) for English language editing.

\section{References}

1 Brahmer J, Reckamp KL, Baas P, Crino L, Eberhardt WE, Poddubskaya E, Antonia S, Pluzanski A, Vokes EE, Holgado E, Waterhouse D, Ready N, Gainor J, Aren Frontera O, Havel L, Steins M, Garassino MC, Aerts JG, Domine M, Paz-Ares L, Reck M, Baudelet C, Harbison CT, Lestini B and Spigel DR: Nivolumab versus docetaxel in advanced squamous-cell non-small-cell lung cancer. N Engl J Med 373: 123-135, 2015.

2 Borghaei H, Paz-Ares L, Horn L, Spigel DR, Steins M, Ready NE, Chow LQ, Vokes EE, Felip E, Holgado E, Barlesi F, Kohlhaufl M, Arrieta O, Burgio MA, Fayette J, Lena H, Poddubskaya E, Gerber DE, Gettinger SN, Rudin CM, Rizvi N, Crino L, Blumenschein GR Jr., Antonia SJ, Dorange C, Harbison $\mathrm{CT}$, Graf Finckenstein $\mathrm{F}$ and Brahmer JR: Nivolumab versus docetaxel in advanced non-squamous-cell non-small-cell lung cancer. N Engl J Med 373: 1627-1639, 2015.

3 Herbst RS, Baas P, Kim DW, Felip E, Perez-Gracia JL, Han JY, Molina J, Kim JH, Arvis CD, Ahn MJ, Majem M, Fidler MJ, de Castro G, Jr., Garrido M, Lubiniecki GM, Shentu Y, Im E, Dolled-Filhart $\mathrm{M}$ and Garon EB: Pembrolizumab versus docetaxel for previously treated, PD-L1-positive, advanced nonsmall-cell lung cancer (KEYNOTE-010): a randomised controlled trial. Lancet 387: 1540-1550, 2016.

4 Friedman CF, Proverbs-Singh TA and Postow MA: Treatment of the immune-related adverse effects of immune checkpoint inhibitors: A review. JAMA Oncol 2: 1346-1353, 2016.

5 Gettinger SN, Horn L, Gandhi L, Spigel DR, Antonia SJ, Rizvi NA, Powderly JD, Heist RS, Carvajal RD, Jackman DM, Sequist LV, Smith DC, Leming P, Carbone DP, Pinder-Schenck MC, Topalian SL, Hodi FS, Sosman JA, Sznol M, McDermott DF, Pardoll DM, Sankar V, Ahlers CM, Salvati M, Wigginton JM, Hellmann MD, Kollia GD, Gupta AK and Brahmer JR: Overall survival and long-term safety of nivolumab (anti-programmed death 1 antibody, BMS-936558, ONO-4538) in patients with previously treated advanced non-small-cell lung cancer. J Clin Oncol 33: 2004-2012, 2015.

6 Topalian SL, Hodi FS, Brahmer JR, Gettinger SN, Smith DC, McDermott DF, Powderly JD, Carvajal RD, Sosman JA, Atkins MB, Leming PD, Spigel DR, Antonia SJ, Horn L, Drake CG, Pardoll DM, Chen L, Sharfman WH, Anders RA, Taube JM, McMiller TL, Xu H, Korman AJ, Jure-Kunkel M, Agrawal S, McDonald D, Kollia GD, Gupta A, Wigginton JM and Sznol M: Safety, activity, and immune correlates of anti-PD-1 antibody in cancer. N Engl J Med 366: 2443-2454, 2012. 
7 Mole RH: Whole body irradiation; radiobiology or medicine? $\mathrm{Br}$ J Radiol 26: 234-241, 1953.

8 Formenti SC and Demaria S: Systemic effects of local radiotherapy. The Lancet Oncol 10: 718-726, 2009.

9 Formenti SC and Demaria S: Combining radiotherapy and cancer immunotherapy: a paradigm shift. J Natl Cancer Inst 105: 256-265, 2013.

10 Golden EB, Demaria S, Schiff PB, Chachoua A and Formenti SC: An abscopal response to radiation and ipilimumab in a patient with metastatic non-small cell lung cancer. Cancer Immunol Res 1: 365-372, 2013.

11 Eisenhauer EA, Therasse P, Bogaerts J, Schwartz LH, Sargent D, Ford R, Dancey J, Arbuck S, Gwyther S, Mooney M, Rubinstein L, Shankar L, Dodd L, Kaplan R, Lacombe D and Verweij J: New Response Evaluation Criteria in Solid Tumours: revised RECIST guideline (version 1.1). Eur J Cancer 45: 228247, 2009.

12 North RJ: Radiation-induced, immunologically mediated regression of an established tumor as an example of successful therapeutic immunomanipulation. Preferential elimination of suppressor T-cells allows sustained production of effector $\mathrm{T}$ cells. J Exp Med 164: 1652-1666, 1986.

13 Demaria S, Ng B, Devitt ML, Babb JS, Kawashima N, Liebes L and Formenti SC: Ionizing radiation inhibition of distant untreated tumors (abscopal effect) is immune mediated. Int $\mathrm{J}$ Radiat Oncol Biol Phys 58: 862-870, 2004.

14 Lee Y, Auh SL, Wang Y, Burnette B, Wang Y, Meng Y, Beckett M, Sharma R, Chin R, Tu T, Weichselbaum RR and Fu YX: Therapeutic effects of ablative radiation on local tumor require $\mathrm{CD}^{+} \mathrm{T}$ cells: changing strategies for cancer treatment. Blood 114: 589-595, 2009.

15 Deng L, Liang H, Burnette B, Beckett M, Darga $T$, Weichselbaum RR and Fu YX: Irradiation and anti-PD-L1 treatment synergistically promote antitumor immunity in mice. J Clin Invest 124: 687-695, 2014.

16 Seetharam S, Staba MJ, Schumm LP, Schreiber K, Schreiber H, Kufe DW and Weichselbaum RR: Enhanced eradication of local and distant tumors by genetically produced interleukin-12 and radiation. Int J Oncol 15: 769-773, 1999.

17 Golden EB, Chhabra A, Chachoua A, Adams S, Donach M, Fenton-Kerimian M, Friedman K, Ponzo F, Babb JS, Goldberg J, Demaria $\mathrm{S}$ and Formenti SC: Local radiotherapy and granulocyte-macrophage colony-stimulating factor to generate abscopal responses in patients with metastatic solid tumours: a proof-of-principle trial. Lancet Oncol 16: 795-803, 2015.

18 Weichselbaum RR, Liang H, Deng L and Fu YX: Radiotherapy and immunotherapy: a beneficial liaison? Nat Rev Clin Oncol 14: 365-379, 2017.
19 Fridman WH, Pages F, Sautes-Fridman C and Galon J: The immune contexture in human tumours: impact on clinical outcome. Nat Rev Cancer 12: 298-306, 2012.

20 Dahan R, Sega E, Engelhardt J, Selby M, Korman AJ and Ravetch JV: FcgammaRs Modulate the Anti-tumor Activity of Antibodies Targeting the PD-1/PD-L1 Axis. Cancer Cell 28: 285-295, 2015.

21 Kato T, Masuda N, Nakanishi Y, Takahashi M, Hida T, Sakai H, Atagi S, Fujita S, Tanaka H, Takeda K, Satouchi M, Namba Y and Tamura T: Nivolumab-induced interstitial lung disease analysis of two phase II studies patients with recurrent or advanced nonsmall-cell lung cancer. Lung cancer 104: 111-118, 2017.

22 Vegesna V, Withers HR, McBride WH and Holly FE: Adriamycin-induced recall of radiation pneumonitis and epilation in lung and hair follicles of mouse. Int J Radiat Oncol Biol Phys 23: 977-981, 1992.

23 Togashi Y, Masago K, Mishima M, Fukudo M and Inui K: A case of radiation recall pneumonitis induced by erlotinib, which can be related to high plasma concentration. J Thorac Oncol 5: 924-925, 2010

24 Schwarte S, Wagner K, Karstens JH and Bremer M: Radiation recall pneumonitis induced by gemcitabine. Strahlenther Onkol 183: 215-217, 2007.

25 Ding X, Ji W, Li J, Zhang X and Wang L: Radiation recall pneumonitis induced by chemotherapy after thoracic radiotherapy for lung cancer. Radiat Oncol 6: 24, 2011.

26 Chiang CL, Chen YW, Wu MH, Huang HC, Tsai CM and Chiu $\mathrm{CH}$ : Radiation recall pneumonitis induced by epidermal growth factor receptor-tyrosine kinase inhibitor in patients with advanced nonsmall-cell lung cancer. J Chin Med Assoc 79: 248$255,2016$.

27 Burris HA, 3rd and Hurtig J: Radiation recall with anticancer agents. Oncologist 15: 1227-1237, 2010.

28 Weber JS, Kahler KC and Hauschild A: Management of immune-related adverse events and kinetics of response with ipilimumab. J Clin Oncol 30: 2691-2697, 2012.

29 Nishino M, Sholl LM, Hodi FS, Hatabu H and Ramaiya NH: Anti-PD-1-related pneumonitis during cancer immunotherapy. N Engl J Med 373: 288-290, 2015.

30 Brown KE, Freeman GJ, Wherry EJ and Sharpe AH: Role of PD-1 in regulating acute infections. Curr Opin Immunol 22: 397-401, 2010.
Received June 21, 2017

Revised August 5, 2017

Accepted August 8, 2017 